\title{
Postoperative myocardial infarction after acute type A dissection: Another day, another database?
}

\author{
Leora B. Balsam, MD, ${ }^{\mathrm{a}}$ and Abe DeAnda, Jr, $\mathrm{MD}^{\mathrm{b}}$
}

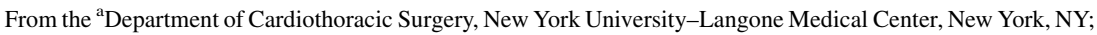
and the ${ }^{\mathrm{b}}$ Division of Cardiothoracic Surgery, University of Texas Medical Branch-Galveston, Galveston, Tex. Disclosures: Authors have nothing to disclose with regard to commercial support.

Received for publication Nov 6, 2016; accepted for publication Nov 8, 2016; available ahead of print Dec 21, 2016.

Address for reprints: Leora B. Balsam, MD, Department of Cardiothoracic Surgery, NYU-Langone Medical Center, 530 First Ave, Suite 9V, New York, NY 10016 (E-mail: leora.balsam @nyumc.org).

J Thorac Cardiovasc Surg 2017;153:528-9

$0022-5223 / \$ 36.00$

Copyright $(2) 2016$ by The American Association for Thoracic Surgery

http://dx.doi.org/10.1016/j.jtcvs.2016.11.009
}

Postoperative complications after the surgical repair of acute type A aortic dissection (ATAAD) relate to a wide spectrum of patient, disease, and procedural factors. Postrepair myocardial infarction (MI) is uncommon and can be the result of preexisting coronary disease, dissection into the coronary ostia, impingement of the ostia by the dissection flap, embolization of debris down one of the coronaries, or surgical misadventure. During the last 2 decades, the International Registry of Acute Aortic Dissection (IRAD) has prospectively collected data that lends insight into the process. ${ }^{1}$ What we now know is that preexisting coronary artery disease is not insignificant in this population, with $5 \%$ of patients having had previous coronary artery bypass grafting and nearly a quarter having a history of atherosclerosis. Moreover, on presentation approximately $60 \%$ of patients have some electrocardiographic abnormality, and $15 \%$ have evidence of preoperative MI or myocardial ischemia. Preoperative malperfusion in these patients, including coronary malperfusion, strongly influences surgical mortality and is a weighted variable in several risk models for early mortality after repair of ATAAD. ${ }^{2}$ An association between the proximal extent of aortic repair and postoperative MI also appears to exist, with a recent IRAD study reporting a rate of postoperative MI of $5.7 \%$ in patients with ATAAD undergoing root replacement versus $2.2 \%$ in those undergoing supracoronary grafting. ${ }^{3}$ In that study, not surprisingly, coronary artery involvement on preoperative imaging was 2 times more common in patients treated with root replacement than in those treated with supracoronary grafting $(20.4 \%$ vs $10.0 \%)$.

In this issue of the Journal, Waterford and colleagues ${ }^{4}$ delve back into the IRAD data and focus specifically on characteristics and outcomes of patients with ATAAD who have postoperative (rather than preoperative) MIs. ${ }^{4}$ Separating these patients out should provide some insight into the preoperative and intraoperative risk factors. In the adult cardiac surgery literature, postoperative $\mathrm{MI}$ is a

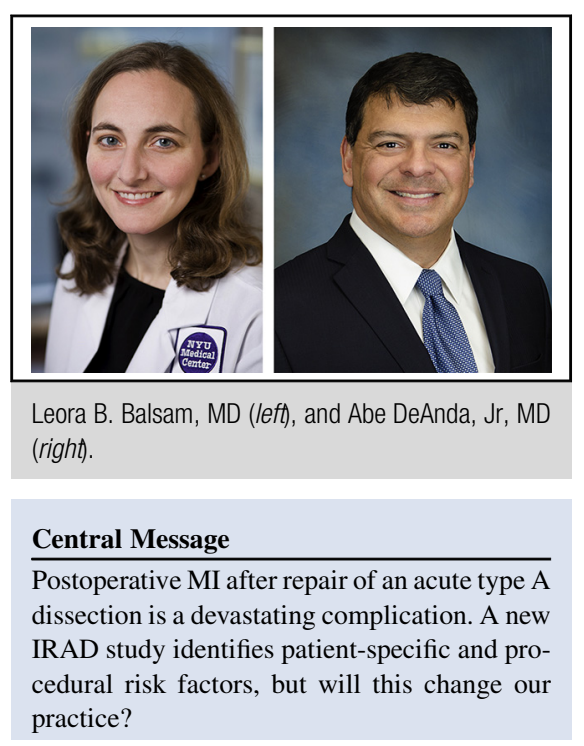

See Article page 521.

well-recognized bad player when it comes to surgical mortality, so one would expect its impact on the ATAAD population to at least mirror that experience. A recent report on the National Inpatient Sample found a 5.4\% frequency of postoperative MI after surgery for ATAAD, with an associated 3.2-fold increase in in-hospital mortality. ${ }^{5}$

Waterford and colleagues ${ }^{4}$ tease apart the IRAD population, focusing on a more "homogeneous" subset without evidence of preoperative coronary ischemia (either new or old). Of 2953 patients with ATAAD enrolled in the database between 1996 and 2013, 49\% met the inclusion criteria. Patients who were not surgically treated $(14 \%)$, had iatrogenic ATAAD $(6 \%)$, had preoperative evidence of MI or myocardial ischemia $(14 \%)$, or had Q waves on electrocardiography $(17 \%)$ were excluded. Among the remaining 1445 patients that made up the study population, only 38 patients (or $2.6 \%$ ) had postoperative MI. A number of preoperative risk factors, which are not necessarily independent of each other, were identified, including history of bicuspid aortic valve, proximal extension of dissection to the level of the aortic root, and larger aortic root and sinotubular junction diameters. On preoperative imaging, pericardial effusion and coronary artery compromise were more common in patients who later had postoperative MI. Procedural risk factors for 
postoperative MI were root replacement, coronary artery bypass grafting, aortic valve replacement, and longer duration of circulatory arrest. Surgical mortality in the patients with postoperative MI was markedly worse than in those without this complication $(57.9 \%$ vs $16.3 \%)$.

The findings of this study parallel those of several large series of aortic root replacement procedures, ${ }^{6-8}$ likely because more than half of these patients with postoperative MI underwent root replacement. In that literature, the rate of postoperative MI has ranged from $2 \%$ to $11 \%$, with a general trend toward lower rates in more recent eras. In these patients, postoperative MI has been a strong predictor of mortality. Factors associated with postoperative MI after root replacement have included concomitant coronary artery bypass grafting, diagnosis of ATAAD, and use of the Cabrol technique for coronary artery reconstruction. Early recognition of technical issues with coronary reimplantation is paramount in preventing postoperative MI in this population and requires unplanned or "rescue" coronary artery bypass grafting when recognized. Myocardial ischemia can become manifest intraoperatively or in the immediate postoperative period with new ventricular wall motion abnormalities, failure to wean from cardiopulmonary bypass, ST-segment elevation, ventricular arrhythmias, or hemodynamic compromise. Such ischemia is considered to be secondary to coronary button malposition or distortion, and when these events are detected and dealt with early, the deleterious impact on survival can be avoided. ${ }^{?}$

The IRAD data offer a view into the characteristics and outcomes of patients with ATAAD, but this view is not without limitations. Currently, 36 centers worldwide voluntarily submit data to this registry, ${ }^{10}$ and data collection occurs both prospectively and retrospectively. In some cases, data collection may be incomplete or inaccurate, depending on the quality of the medical record. Whether this experience represents the "real world" experience with ATAAD also remains a matter of debate. It is clear that many high-volume aortic centers do not participate in IRAD, but it is also clear that most low-volume centers also do not participate. In the end, one wonders whether the decision by Waterford and colleagues ${ }^{4}$ to focus solely on the patients with postoperative MI (and to exclude those with preoperative evidence of ischemia, either new or old), really makes clinical sense. Can the 2 types of MI really be distinguished, and more importantly, should they be? And with such a low event rate, despite their efforts, Waterford and colleagues ${ }^{4}$ cannot make meaningful conclusions about the intermediate-term or long-term survival after postoperative MI.

What are the lessons learned from this new IRAD study? Postoperative MI portends a bad outcome after surgical repair of ATAAD. Few of the identified risk factors are modifiable, but as surgeons, one area to focus on is the technical execution of coronary artery implantation during root replacement. Avoidance of errors during this step (and quick recognition when they occur) will likely save some lives.

\section{References}

1. Pape LA, Awais M, Woznicki EM, Sukuki T, Trimarchi S, Evangelista A, et al Presentation, diagnosis, and outcomes of acute aortic dissection: 17-year trends from the International Registry of Acute Aortic Dissection. J Am Coll Cardiol. 2015;66:350-8.

2. Rampoldi V, Trimarchi S, Eagle KA, Nienaber CA, Oh JK, Bossone E, et al. International Registry of Acute Aortic Dissection (IRAD) Investigators. Simple risk models to predict surgical mortality in acute type A aortic dissection: the International Registry of Acute Aortic Dissection score. Ann Thorac Surg. 2007:83:55-61.

3. Di Eusanio M, Trimarchi S, Peterson MD, Myrmel T, Hughes GC, Korach A et al. Root replacement versus more conservative management during type A acute aortic dissection repair. Ann Thorac Surg. 2014;98:2078-85.

4. Waterford SD, Di Eusanio M, Ehrlich MP, Reece B, Desai ND, Sundt TM, et al. Postoperative myocardial infarction in acute type A aortic dissection: a report from the International Registry of Acute Aortic Dissection. J Thorac Cardiovasc Surg. 2017:153:521-7.

5. Zimmerman KP, Oderich G, Pochettino A, Hanson KT, Habermann EB, Bower TC, et al. Improving mortality trends for hospitalization of aortic dissection in the National Inpatient Sample. J Vasc Surg. 2016;64:606-15.e1.

6. van Putte BP, Ozturk S, Siddiqi S, Schepens MA, Heijmen RH, Morshuis WJ. Early and late outcome after aortic root replacement with a mechanical valve prosthesis in a series of 528 patients. Ann Thorac Surg. 2012;93:503-9.

7. Di Marco L, Pacini D, Pantaleo A, Leone A, Barberio G, Marinelli G, et al. Composite valve graft implantation for the treatment of aortic valve and root disease: results of 1045 patients. J Thorac Cardiovasc Surg. 2016;152:1041-8.e1.

8. Byrne JG, Karavas AN, Leacche M, Unic D, Rawn JD, Couper GS, et al. Impact of concomitant coronary artery bypass grafting on hospital survival after aortic root replacement. Ann Thorac Surg. 2005;79:511-6.

9. Shahriari A, Eng M, Tranquilli M, Elefteriades JA. Rescue coronary artery bypass grafting (CABG) after aortic composite graft replacement. J Card Surg. 2009;24:392-6.

10. International Registry of Acute Aortic Dissection. Information for patients from the International Registry of Acute Aortic Dissection: IRAD investigators. Available at: http://www.iradonline.org/irad.html\#investigators. Accessed November 5, 2016. 